\title{
Hexarotor Longitudinal Flight Control with Deep Neural Network, PID Algorithm and Morphing
}

\author{
Oguz Kose $^{1 *}$, Tugrul Oktay ${ }^{2}$ \\ 1* Gumushane University, School of Applied Sciences, Department of Aviation Management, Gumushane, Turkey, (ORCID: 0000-0002-8069-8749), \\ oguzkose24@gmail.com \\ ${ }^{2}$ Erciyes University, Departmant of Aeronautical Engineering, Kayseri, Turkey, (ORCID: 0000-0003-4860-2230), tugruloktay52@gmail.com
}

(First received 2 June 2021 and in final form 15 August 2021)

(DOI: 10.31590/ejosat.946884)

ATIF/REFERENCE: Kose, O., Oktay, T. (2021). Hexarotor Longitudinal Flight Control with Deep Neural Network, PID Algorithm and Morphing. European Journal of Science and Technology, (27), 115-124.

\begin{abstract}
Unmanned Aerial Vehicles (UAV) have become an integral part of life, from military operations to entertainment. With this popularity, the interest of researchers on these UAVs has gradually increased. The use of UAVs in many areas and the researches carried out by researchers have revealed the limitations of these devices. At the beginning of these restrictions is the passage through the narrow space. In this study, longitudinal flight control of a hexarotor UAV is discussed with morphing. The limitation of this study is that it is difficult to estimate the moment of inertia and proportional integral derivative (PID) coefficient values according to the arm length, since there is a change in the hexarotor arm lengths with the morphing and the rigid body model changes accordingly. In this study, it is aimed to obtain these parameters with the Deep Neural Network(Artificial Neural Network(ANN) with two or more hidden layers) to overcome this problem. 15 drawings of hexarotor morphing states were drawn in Solidworks program. A training set was created by obtaining the PID coefficients for the longitudinal flight of these drawings from the Matlab/Simulink program. The training set was taught to the Deep Neural Network and moments of inertia and PID coefficients were obtained according to the arbitrarily estimated arm extension or shortening rates. In addition, the hexarotor dynamic model was derived according to the Newton-Euler approach and modeled using the state space model. The longitudinal flight of the hexarotor is simulated with the state space model. The moment of inertia and PID coefficients were estimated by Deep Neural Network according to the values determined by the program randomly together with the initial state. Simulations were made with these parameters and the results were given in graphics.
\end{abstract}

Keywords: Hexarotor, Deep Neural Network, PID, UAV, Control, Artificial Neural Network.

\section{Deep Neural Network, PID Algoritması ve Başkalaşım ile Hexarotor Boylamasına Uçuş Kontrolü}

$\ddot{O} z$

İnsansız Hava Araçları (IHA) günümüzde askeri operasyonlardan eğlenceye kadar yaşamın ayrılmaz bir parçası durumuna gelmşitir. Bu popülerite ile birlikte araştırmacıların da bu İHA'lar üzerine olan ilgisi giderek artmıştır. İHA'lar birçok alanda kullanılması ve araştırmacılar tarafilan yapılan araştırmalar bu cihazların da kısıtlamalarını ortaya çıkarmıştır. Bu kısıtlamaların başında özellikle dar alandan geçiş gelmektedir. Bu çalışmada bir hexarotor İHA'ın boylamasına uçuş kontrolü başkalaşım ile ele alınmıştır. Bu çalışmada ki kısıt ise başkalaşım ile birlikte hexarotor kol uzunluklarında değişim olması ve buna bağlı olarak katı cisim modeli değiştiğinden dolayı atalet momenti ve oransal integral türev(PID) katsayı değerlerinin kol uzunluğuna göre tahmin edilmesinin zor olmasıdır. Bu çalışmada bu sorunun üstesinden gelmek için Derin Sinir Ağı(iki yada daha fazla hidden layer içeren yapay sinir ağı) ile bu parametrelerin elde edilmesi amaçlanmıştır. Hexarotor başkalaşım durumlarına ait 15 adet çizim Solidworks programında çizilmiş̧ir. Bu çizimlere ait boylamasına uçuş için PID katsayıları ise Matlab/Simulink programından elde edilerek bir eğitim seti oluşturulmuş̧ur. Eğitim seti Derin Sinir Ağına öğretilerek rasgele olarak tahmin edilen kol uzama ya da kısalma oranlarına göre atalet momentleri ve PID katsayıları elde edilmiştir. Ayrıca hexarotor dinamik modeli ise Newton-Euler yaklaşımına göre türetilmiş ve durum uzay modeli kullanılarak modellenmiştir. Durum uzay modeli ile hexarotor boylasına uçuş simülasyonu gerçekleştirilmiş̧ir. Başlangıç durumu ile birlikte rasgele olarak program tarafindan belirlenen değerlere göre atalet momenti ve PID katsayıları Deep Neural Network ile tahmin edilmiştir. Bu parametreler ile simülasyonlar yapılarak sonuçlar grafikler halinde verilmiştir.

Anahtar Kelimeler: Hexarotor, Derin Sinir Ağı, PID, İHA, Kontrol, Yapay Sinir Ağı.

*Corresponding Author: oguzkose24@gmail.com 


\section{Introduction}

In recent years, with the developing technology, UAVs have become an integral part of life. With this situation, the researchers concentrated their studies on UAVs. UAVs with high maneuverability, structurally simple and cheaper have started to be popular with hobbyists and institutions(Çoban et al., 2019). This type of UAVs have become used in many areas from security to entertainment, from the transportation sector to military operations. In addition, since they are frequently used in areas such as search and rescue and debris detection in regions damaged by natural disasters, they eliminate the risk of life in their pilots(Alaimo et al., 2013).

Hexarotors, one of the UAVs with more rotors than the existing four rotors, are one of the most preferred vehicles in this field. The features that make hexarotor stand out from other UAVs can be listed as payload, maneuverability, more power with six rotors and more lift(Le et al., 2015).

In recent years, many studies have been done on hexarotor modeling, control and simulation. Pflimlin et al., 2007, despite unknown aerodynamic effects and side winds, VTOL took control of an aircraft. The proposed approach aims to overcome the gyroscopic connection problem by utilizing both the thrust mechanism structure and the deviation velocity effect. The designed controller was designed using backstepping techniques that allow fixing the position of the vehicle while predicting unknown aerodynamic effects. Ko et al., 2017 worked on a hexacopter autopilot and its design. They used the PID controller structure in the designed autopilot system. While controlling the roll and yaw movements in the control structure, they also stored the flight data of these movements. Wang et al., 2017 presented a new approach that automatically adjusts PID parameters in the hexacopter. In an experimental test apparatus, the hexarotor inputs and outputs were safely collected and sent to the PID controller structure with the feedback method. He compared the proposed method with the Ziegler-Nichols method. It demonstrated its success by testing the experimental results in the external environment. Sanca et al., 2010 discusses a dynamic model with nonlinear outputs and a hexarotor with backstepping method. The aim was to obtain a mathematical representation of the system not only in hover, but also during take-off and flight. The model has been implemented in Matlab / Simulink environment. Hexarotor simulation model demonstrates the control law and trajectory tracking performance. Oktay et al., 2017 has discussed the multirotor unmanned aerial vehicle for different flight situations. The multirotor mathematical model for longitudinal, lateral and vertical take off and landing is shown by the state space model. Simulations of the control system using PID as a controller were carried out in Matlab / Simulink environment. Multirotor full model drawings were carried out in the Solidworks program. Kose et al., 2020a, 2020b, 2020c, 2020d applied the morphing case on the multirotor. In the system where PID is used as the multirotor control algorithm, the full multirotor model and morphing cases are drawn separately in the Solidworks program. In simulations made in Matlab / Simulink environment using state space model approach, multirotor has been successfully controlled in hover, yaw, longitudinal and lateral flight.

In this article, the hexarotor autopilot system is designed for longitudinal flight simultaneously with the artificial nural network, active morphing and PID controller. The hexarotor model was created with the state space model approach using the
Newton-Euler approach. Simulations were carried out in Matlab / Simulink environment. Hexarotor full model and morphing models were drawn using the Solidworks program. It is difficult to determine the PID coefficients for longitudinal flight according to the morphing state. ANN has been used to overcome this situation. Several morphing states of the hexarotor and values such as the moment of inertia and PID coefficients related to these conditions were obtained. Since these values change according to the arm length, the arm length value constitutes an input value for ANN. A data set including arm length, moments of inertia and PID coefficients was created with the values obtained from experimental data. Using learning models with ANN, it was obtained which moment of inertia value and PID coefficient values would be suitable for which morphing situation. With this method, hexarotor longitudinal flight was carried out under morphing conditions. This article is one of the few studies addressing the morphing state for the hexarotor literature.

\section{Material and Method}

\subsection{Hexarotor Modelling and Morphing}

It is a type of UAV that belongs to a hexarotor multirotor family. Hexarotor model has a symmetrical structure and rigid body. Hexarotor has 6 arms of the same length placed from the center towards the corners of the hexagon. There is a brushless motor at the end of each arm and a propeller is attached to each brushless motor. The hexarotor is symmetrical due to its structure and the hexarotor's center of gravity is in the center of the hexagon. It has six arms, motors and propellers due to its hexagonal structure. Three of the propellers rotate clockwise while the other three rotate counterclockwise. Also, the blade on each propeller is fixed pitch. Hexarotor structure and propeller rotation directions are shown in the figure below.

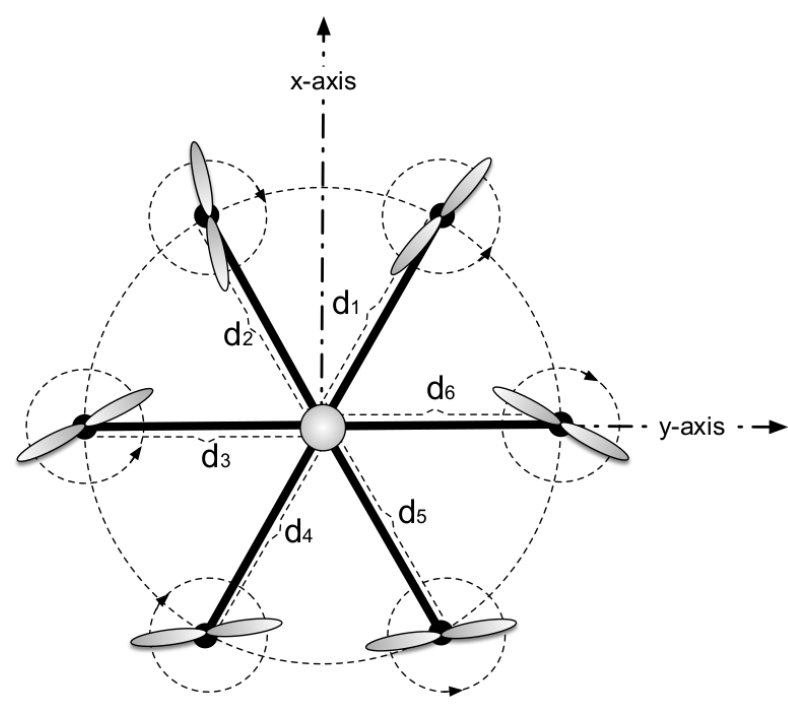

Figure 1. Hexarotor model

Hexarotor movements are controlled by changing the angular velocities of the propellers. Each propeller pushes the air down, producing a separate thrust. The source of thrust is outside the center of gravity. Upward thrusts are used to give motion to the hexarotor. In addition to thrust, a reaction torque arises that is opposite to the motor rotation direction. Three rotors rotating in the same direction and three other rotors rotating opposite to them provide a torque. If all rotors rotate at the same angular speed, the total torque will be zero. 
In this article, hexarotor longitudinal flight or pitch movement is discussed. Longitudinal movement is called the movement of the hexarotor on the $\mathrm{Y}$ axis as the center of the rotational axis. It is based on the principle of changing the angular velocities of the propellers in the longitudinal movement as in other movements. Since the two propellers in the hexarotor are on the y axis, it will not have any effect on thrust or motion. However, longitudinal movement is achieved by changing the angular velocities of the propellers above and below the y-axis. In Figure 1 , let's assume that the $\mathrm{x}$-axis direction points to the hexarotor front. If the speed of the $\mathrm{d} 1$ and $\mathrm{d} 2$ rotors is decreased and the speed of the $\mathrm{d} 4$ and $\mathrm{d} 5$ rotors is increased, the hexarotor will perform longitudinal motion.

As shown in Figure 2, two coordinate systems are used to describe the motion of a hexarotor: earth fixed frame, body fixed frame.

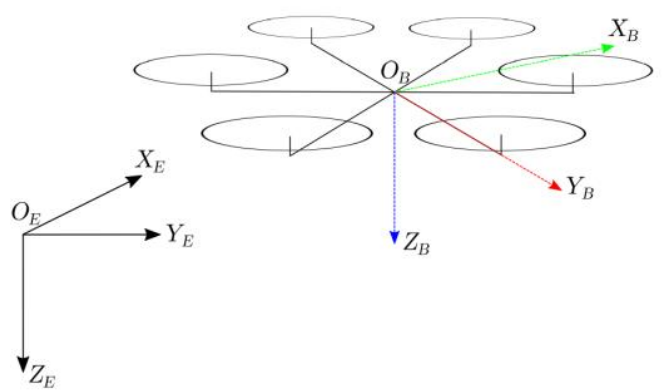

\section{Figure 2. Hexarotor coordinate system}

The Earth fixed frame is denoted by $E$ and represents NED (North, East, and Down). Its origin expressed in $O_{E}$ is considered to be coincident with the earth's surface in the starting position of the hexarotor. The body fixed frme is denoted $B$ and is coincident with its origin, $O_{B}$ hexarotor center. The body fixed frame moves according to the earth fixed frame when the hexarotor moves.

Body fixed frame position on the earth fixed frame;

$$
\xi_{E}=(x, y, z)^{T}
$$

The body fixed frame orientation on the earth fixed frame;

$$
\eta_{E}=(\varphi, \theta, \psi)^{T}
$$

where the angles $\varphi, \theta$ and $\psi$ are called roll, pitch and yaw respectively. These angles are the Euler rotation angles.

Hexarotor position and orientation can be defined as a second-order differential equation set as follows:

$$
\begin{gathered}
\ddot{x}=(\cos \phi \cos \theta \cos \psi+\sin \phi \sin \psi) \frac{U_{1}}{m} \\
\ddot{y}=(\cos \phi \sin \theta \sin \psi-\sin \phi \cos \psi) \frac{U_{1}}{m} \\
\ddot{z}=-g+(\cos \phi \cos \theta) \frac{U_{1}}{m} \\
\ddot{\phi}=\frac{I_{y}-I_{z}}{I_{x}} \dot{\theta} \dot{\psi}+\frac{J_{m}}{I_{x}} \omega_{G} \dot{\theta}+\frac{U_{2}}{I_{x}} \\
\ddot{\theta}=\frac{I_{z}-I_{x}}{I_{y}} \dot{\phi} \dot{\psi}+\frac{J_{m}}{I_{y}} \omega_{G} \dot{\phi}+\frac{U_{3}}{I_{y}} \\
\ddot{\psi}=\frac{I_{x}-I_{y}}{I_{z}} \dot{\theta} \dot{\phi}+\frac{U_{4}}{I_{x}}
\end{gathered}
$$

In these equations, $\cos =$ cosine, $\sin =$ sine, $g$ gravitational acceleration, $\mathrm{m}$ hexarotor mass, $I_{x}, I_{y}$ and $I_{z}$ respectively hexarotor moment of inertia, $U_{1}, U_{2}, U_{3}, U_{4}$ represent the hexarotor control inputs. Since longitudinal flight is considered in this study, only the $U_{3}$ input will be used.

$$
\begin{gathered}
U_{3}=\frac{b l \sqrt{3}}{2}\left(-\omega_{1}^{2}+\omega_{3}^{2}+\omega_{4}^{2}-\omega_{6}^{2}\right) \\
\omega_{G}=-\omega_{1}+\omega_{2}-\omega_{3}+\omega_{4}-\omega_{5}+\omega_{6}
\end{gathered}
$$

Hexarotor is a system with nonlinear dynamics. Using a variety of techniques, nonlinear equations of motion are converted into linear equations. In nonlinear equations, parameters converging to zero are removed from the equation system and linear equations are obtained. Below are the linear motion equations used in the hexarotor system.

$$
\begin{gathered}
\ddot{x}=g \theta \\
\ddot{y}=-g \phi \\
\ddot{z}=-g+\frac{U_{1}}{m} \\
\ddot{\phi}=\frac{U_{2}}{I_{x}} \\
\ddot{\theta}=\frac{U_{3}}{I_{y}} \\
\ddot{\psi}=\frac{U_{4}}{I_{z}}
\end{gathered}
$$

In this study, since the longitudinal movement is controlled, the variable $\ddot{\theta}$ is kept under control.

Morphing is a new and developmental feature for UAV systems. Morphing is generally applicable for all UAVs. Morphing is defined as the changes that UAVs cause in their geometric shapes while on the ground or in the air. Morphing is directly related to the aerodynamic nature of the UAV. Hexarotortype UAVs are also performed as morphing arm lengthening or shortening. A UAV with morphing feature can save battery, work at longer ranges and adjust the payload it carries according to its aerodynamic structure by adjusting its aerodynamic structure according to its own algorithm.

In this study, a hexarotor morphing case is discussed. The morphing case was realized by lengthening or shortening the hexarotor arms. In the case of morphing, the aerodynamic structure will be directly affected as the hexarotor arm lengths change. With morphing, arm length changes and its distance from the rotation axis changes. This causes a change in the hexarotor moments of inertia. Moments of inertia are used as parameters directly used in equations of motion(Oktay et al., 2017). The morphing cases of a hexarotor are shown in the figure below. 


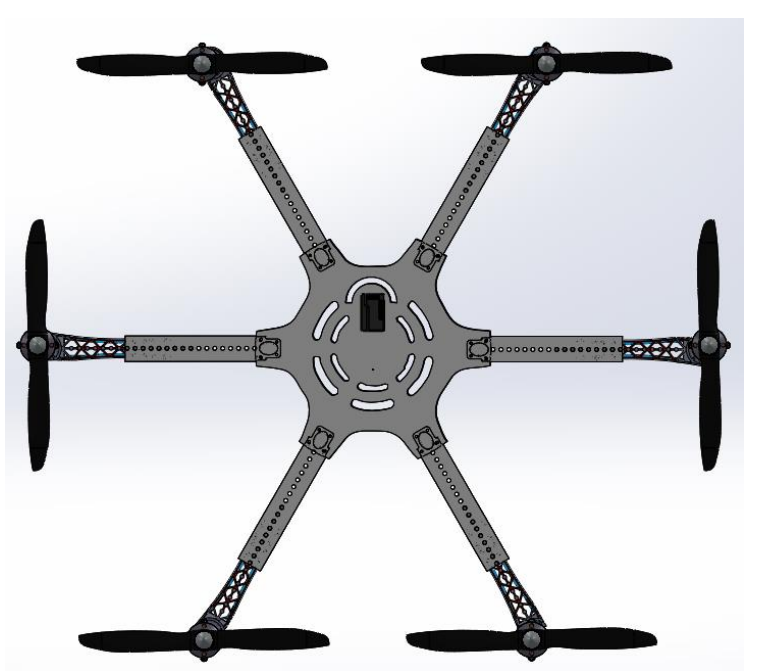

(a)

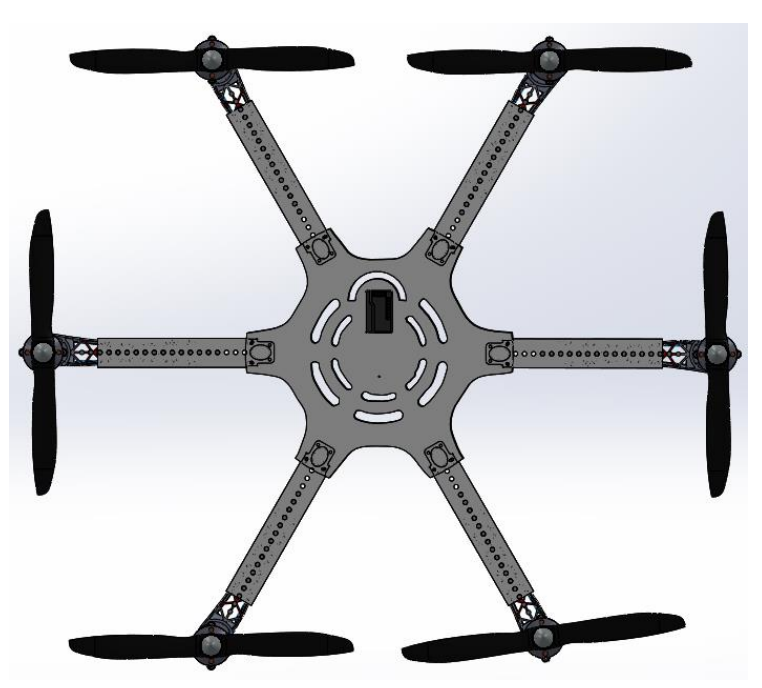

(b)

Figure 3. (a) Hexarotor normal state, (b) Hexarotor morphing state

Hexarotor has an outer arm. It has an inner arm that moves inside the outer arm. The inner arm moves inside the outer arm to perform the morphing process. With each morphing step, the arms lengthen or shorten by $1.5 \mathrm{~cm}$. Hexarotor arms have a length of $41.4 \mathrm{~cm}$ in the initial state. While this length is $51.9 \mathrm{~cm}$ when the arms are fully expanded, it is $30.9 \mathrm{~cm}$ when the arms are fully closed. In the case of morphing, the hexarotor mass remains constant at $1812 \mathrm{~g}$. This mass includes all equipment such as hexarotor controller, battery, GPS.

Changes in arm lengths result in a change in moment of inertia. The moment of inertia is a property that every object that can be rotated has. It is a scalar quantity that describes how difficult it is to change the angular velocity of an object with a given axis of rotation. In this case, the equation for the mass inertia matrix of the hexarotor will be written diagonally as follows.

$$
I=\left[\begin{array}{ccc}
I_{x} & 0 & 0 \\
0 & I_{y} & 0 \\
0 & 0 & I_{z}
\end{array}\right]
$$

Arm lengths, hexarotor mass and moments of inertia of the data taken for the test are shown in the table below.

Table 1. Hexarotor mass, arm length and moment of inertia

\begin{tabular}{c|c|c|c|c|c}
\hline State & Mass(kg) & Length(m) & $\begin{array}{c}\boldsymbol{I}_{\boldsymbol{x}}(\mathbf{k g} * \\
\left.\mathbf{m}^{2}\right)\end{array}$ & $\begin{array}{c}\boldsymbol{I}_{\boldsymbol{y}}(\mathbf{k g} * \\
\left.\boldsymbol{m}^{2}\right)\end{array}$ & $\begin{array}{c}\boldsymbol{I}_{\mathbf{z}}(\mathbf{k g} * \\
\left.\boldsymbol{m}^{2}\right)\end{array}$ \\
\hline 1 & 1.81289 & 0.519 & 0,47 & 0,47 & 0,12 \\
\hline 2 & 1.81289 & 0.504 & 0,47 & 0,47 & 0,11 \\
\hline 3 & 1.81289 & 0.489 & 0,47 & 0,47 & 0,11 \\
\hline 4 & 1.81289 & 0.474 & 0,47 & 0,47 & 0,11 \\
\hline 5 & 1.81289 & 0.459 & 0,47 & 0,47 & 0,1 \\
\hline 6 & 1.81289 & 0.444 & 0,46 & 0,46 & 0,1 \\
\hline 7 & 1.81289 & 0.429 & 0,46 & 0,46 & 0,1 \\
\hline 8 & 1.81289 & 0.414 & 0,46 & 0,46 & 0,09 \\
\hline 9 & 1.81289 & 0.399 & 0,46 & 0,46 & 0,09 \\
\hline 10 & 1.81289 & 0.384 & 0,46 & 0,46 & 0,09 \\
\hline 11 & 1.81289 & 0.369 & 0,46 & 0,46 & 0,08 \\
\hline 12 & 1.81289 & 0.354 & 0,45 & 0,45 & 0,08 \\
\hline 13 & 1.81289 & 0.339 & 0,45 & 0,45 & 0,08 \\
\hline 14 & 1.81289 & 0.324 & 0,45 & 0,45 & 0,07 \\
\hline 15 & 1.81289 & 0.309 & 0,45 & 0,45 & 0,07 \\
\hline
\end{tabular}

\subsection{Control System and Deep Neural Network}

PID control form is a process control method frequently used in industry. The working function of the PID control algorithm is to receive feedback from the controlled process at certain intervals and to correct the control output of the process as a result of the feedback received. Devices working with PID are devices with high sensitivity and adaptability and can be used safely in many applications. The control functions that make up the PID; They are Proportional, Integral and Derivative.

The general structure of PID control is as follows:

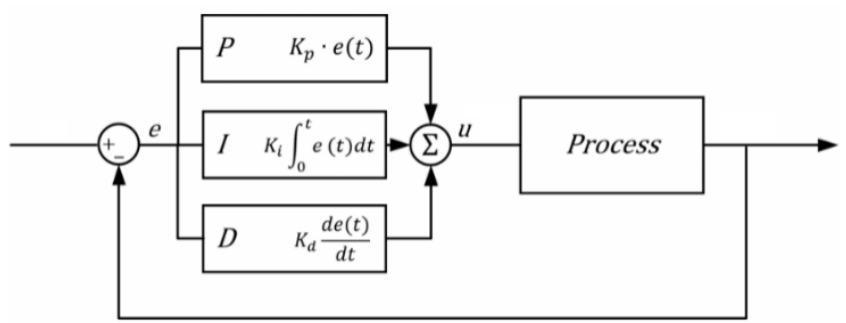

Figure 4. PID structure

The general formulation of PID is given in the equation below.

$$
u(t)=K_{p} e(t)+K_{i} \int_{0}^{t}(t) d(t)+K_{d} d e(t) / d(t)
$$

Artificial neural networks are structures that mimic the brain mechanism. Since the brain is made up of numerous neuron connections, the neural network is formed by the connections of nodes, which are elements that correspond to the brain's neurons. Neural networks use weight values to imitate neurons, the most important mechanism of the brain. The nodes of the input layer merely act as the passage that transmits the input signals to the next nodes. The table below summarizes the similarity between the brain and neural networks. 
Table 2. Brain and ANN

\begin{tabular}{c|c}
\hline Brain & ANN \\
\hline Neuron & Node \\
\hline Connection of Neurons & Connection Weight \\
\hline
\end{tabular}

The figure below shows the structure of the neural network with 3 inputs and 1 output.

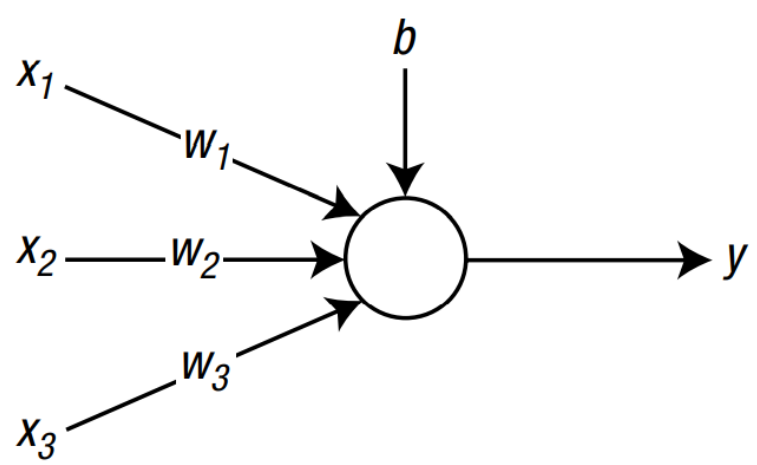

Figure 5. The structure of the neural network with 3 inputs and 1 output

Here $x_{1}, x_{2}$ and $x_{3}$ are the input signals. $w_{1}, w_{2}$ and $w_{3}$ are the weights of the input signals. $b$, on the other hand, represents the bias value, which is the factor related to information storage. $y$ is calculated as the output.

As shown in the figure below, one of the most commonly used types of neural networks is the layered node structure.

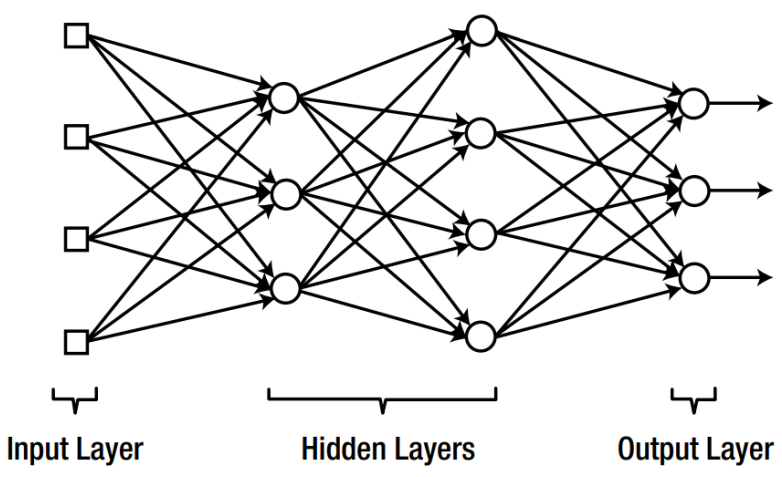

Figure 6. Layered node structure

The layer between the input and output layers is called hidden layers. Because this layer cannot be accessed from outside neural networks. Multilayer neural networks contain two or more hidden layers. These neural networks are called Deep Neural Networks. Most of the modern neural networks used in practical applications are deep neural networks. In a multilayer neural network or Deep Neural Network, the signal enters at the input layer, passes through the hidden layers, and exits at the output layer. During this process, the signal progresses layer by layer. Nodes in one layer receive the signal simultaneously and send the processed signal to the next layer.

In this article, hexarotor moments of inertia and control parameters are obtained according to arm length using deep neural networks. Two hidden layers are used in the deep neural network used. 15 data in Table 1 containing hexarotor morphing cases were drawn in the solidworks program and used as training and validation data for deep neural network. Of the 15 data, $70 \%$ was used for training data and $30 \%$ was used for validation data. The flowchart of the program is shown in the figure below.

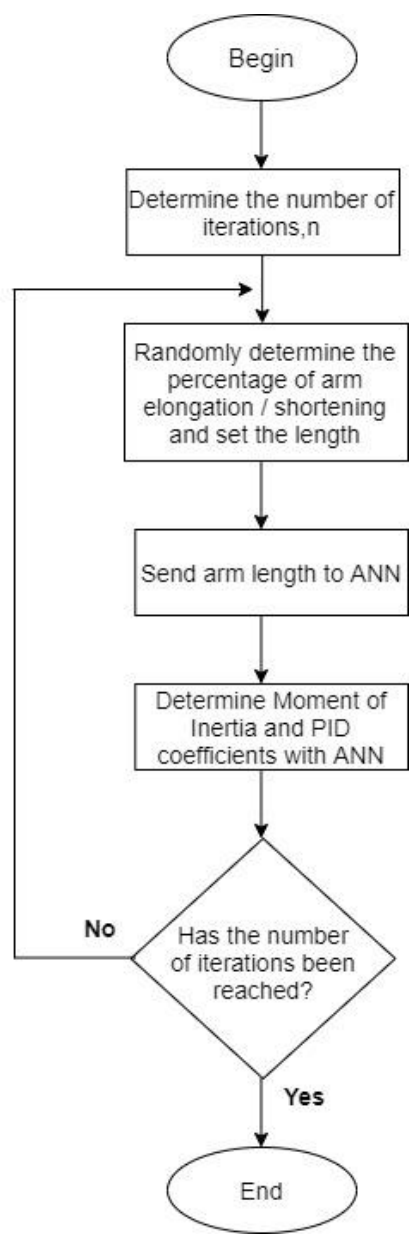

Figure 7. Program flowchart

The Deep Neural Network structure is shown in figure 8 . Here it is possible to see the hidden layer and the number of neurons.

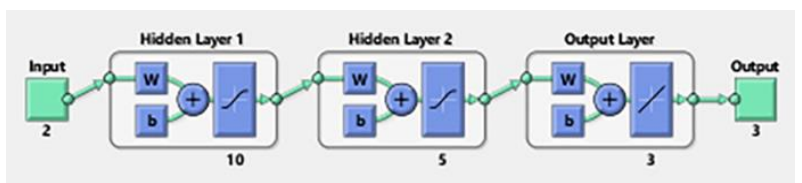

Figure 8. Deep Neural Network structure

Randomly, the percentage of arm lengthening or shortening occurs at the beginning of each iteration. Here, values between 100 and +100 are determined as random values. In the initial state, the hexarotor arms are positioned exactly at the midpoint of 41.4 $\mathrm{cm}$. Morphing is achieved by moving an inner arm with a length of $30.9 \mathrm{~cm}$. There is $10.5 \mathrm{~cm}$ for the lengthening and shortening of the arm. If the random value is between -100 and 0 , the arm is shortened, and if it is between 0 and 100 , the arm is extended. The arm elongation and shortening values are calculated on the remaining arm elongation and shortening values in each iteration. For example; If there is a random value of -40 for the initial state, the new state of the arms is calculated as follows:

- Since it is between -100 and 0 , the arm will be shortened.

- Since it is the initial state, the value of $10.5 \mathrm{~cm}$ is taken

- The amount of shortening is calculated, it is shortened by $10.5 \times 40 / 100=4.2 \mathrm{~cm}$. 
- With shortening, the arm's future position is calculated, $10.5-4.2=6.3 \mathrm{~cm}$

- Since the arm is shortened, $6.3 \mathrm{~cm}$ of shortening remains in the next iteration.

- Elongation margin is calculated, there will be $10.5+4.2=14.7 \mathrm{~cm}$ elongation margin.

- The new arm length is calculated, $6.3+30.9=37.2 \mathrm{~cm}$ becomes the new arm length.

- In the next iteration, the new values are calculated over the shortening margin and elongation margin.

- PID coefficients and new moment of inertia values are obtained by sending the new arm length to the deep neural network.

\section{Results and Discussion}

6 values were randomly estimated for the algorithm. 6 values were randomly estimated for the algorithm. Random values between -100 and +100 are as follows.

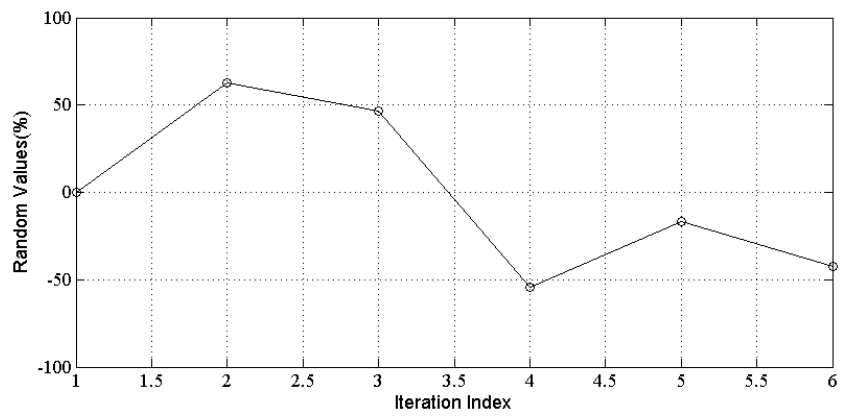

Figure 9. Random values

The hexarotor arm length changes according to the random values will be as follows.

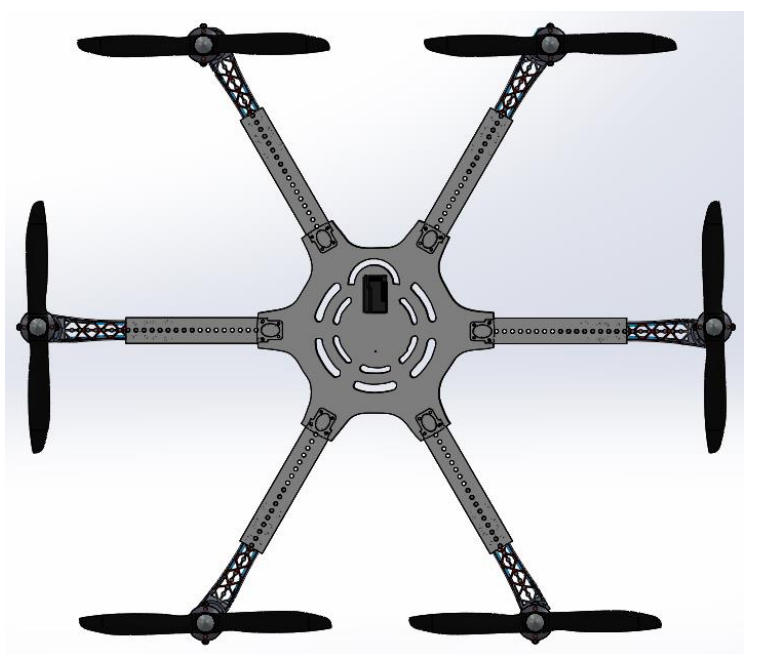

(a)

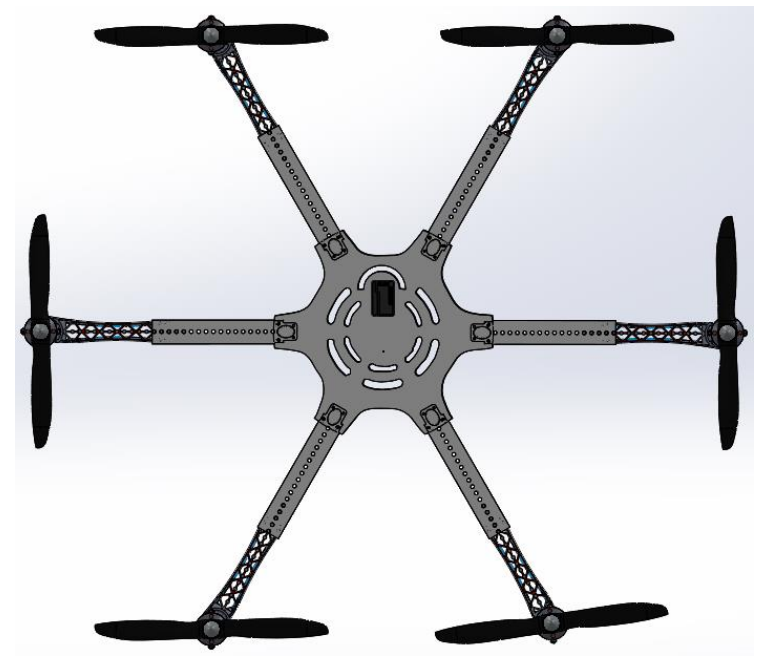

(b)

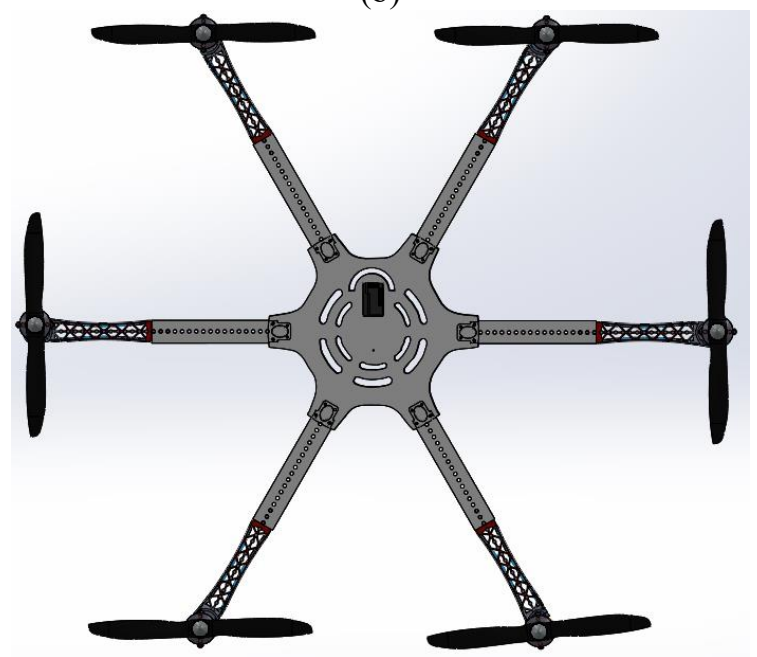

(c)

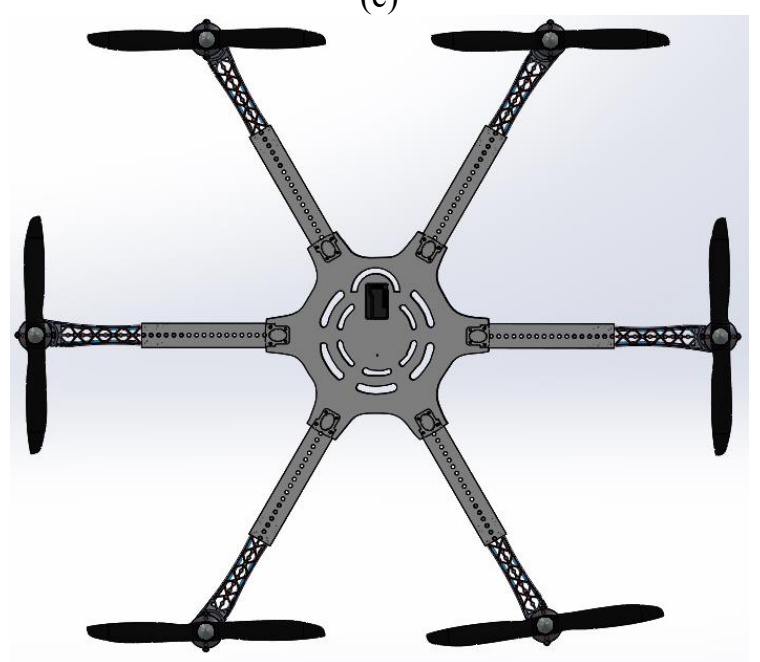

(d) 


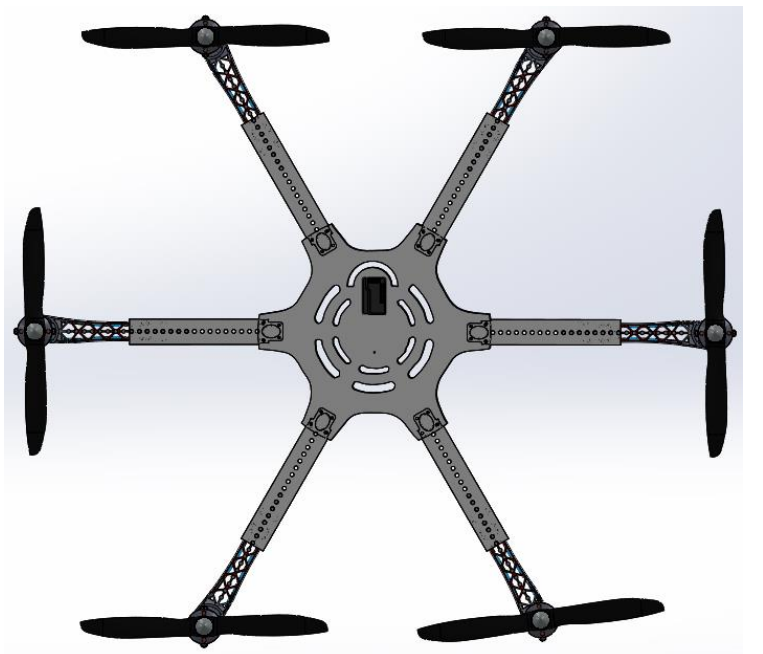

(e)

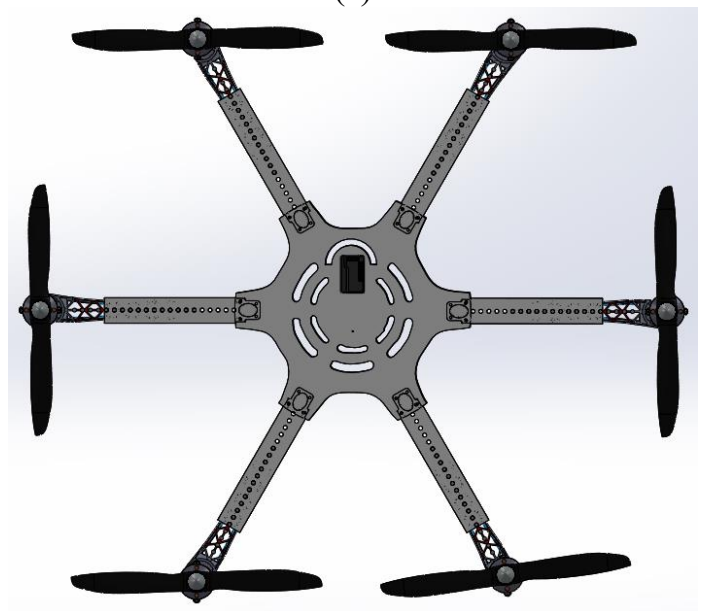

(f)

Figure 10. Hexarotor arm length change

Arm lengths calculated according to random values are as follows.

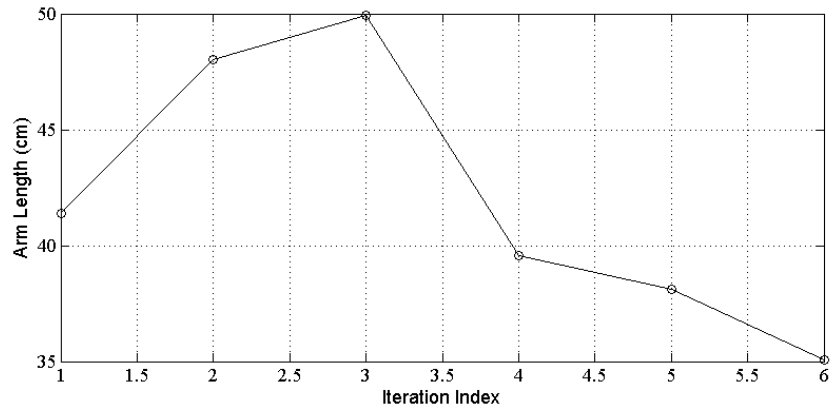

Figure 11. Hexarotor arm length

How much extension and shortening of the arm according to random values in each iteration is shown below.

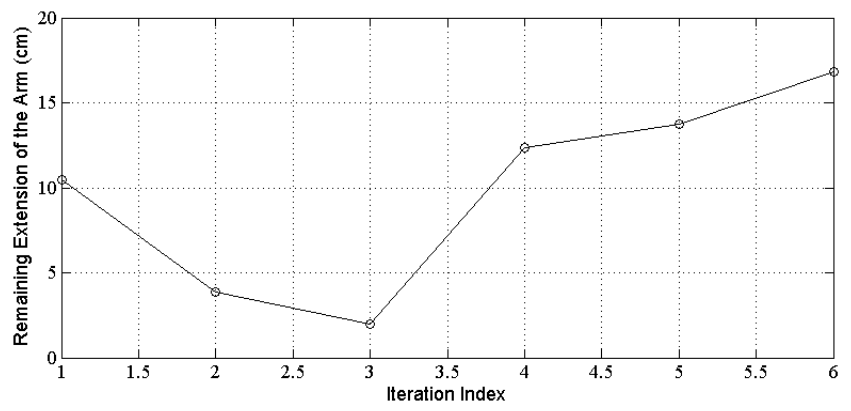

(a)

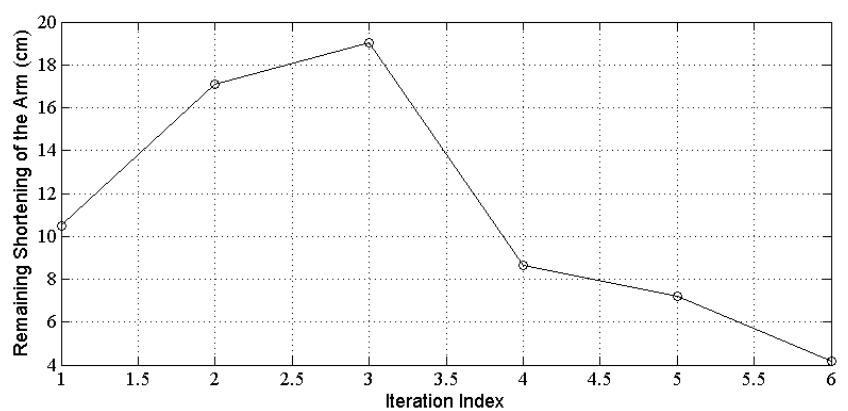

(b)

Figure 12. (a) Remaining amount of extension, (b) Remaining shortening

The arm length calculated in each iteration was sent to the deep neural network and the moments of inertia and PID coefficients were obtained here. The moment of inertia and PID coefficients returned from the deep neural network are given in the graph below for each iteration.

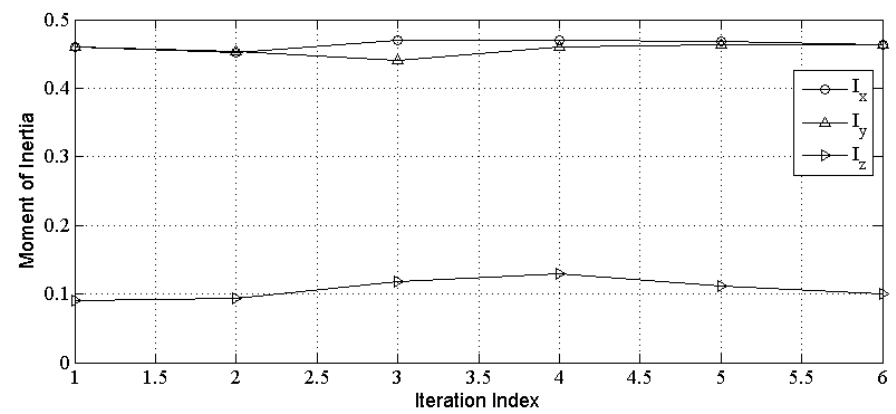

(a)

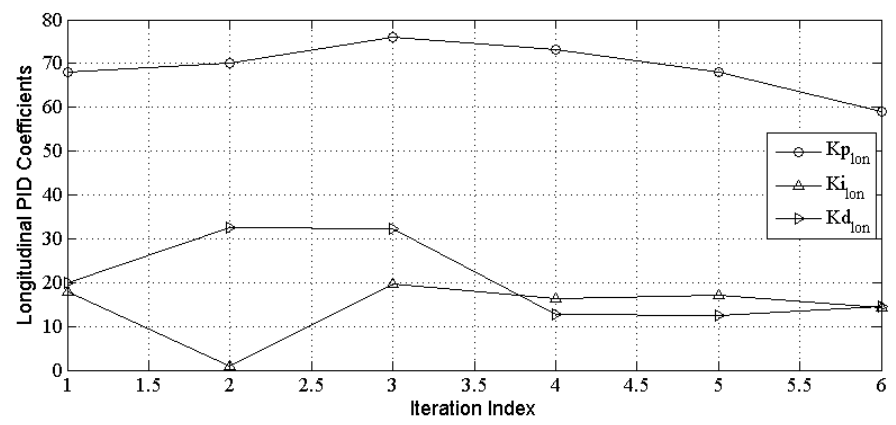

(b)

Figure 13. (a)Moment of inertia, (b)PID coefficients 
For the moment of inertia and PID coefficients obtained with the deep neural network, a hexarotor longitudinal flight of $1^{\circ}$ is simulated with these values in each iteration. The simulation results gave the following results for each iteration.

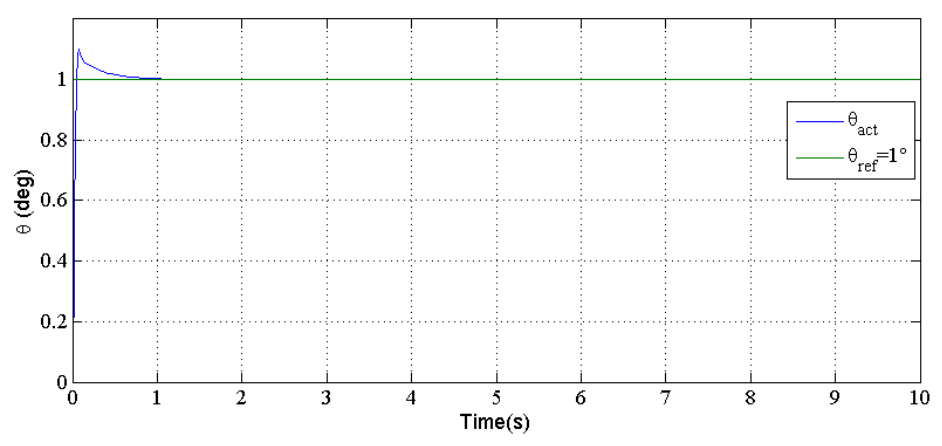

(a)

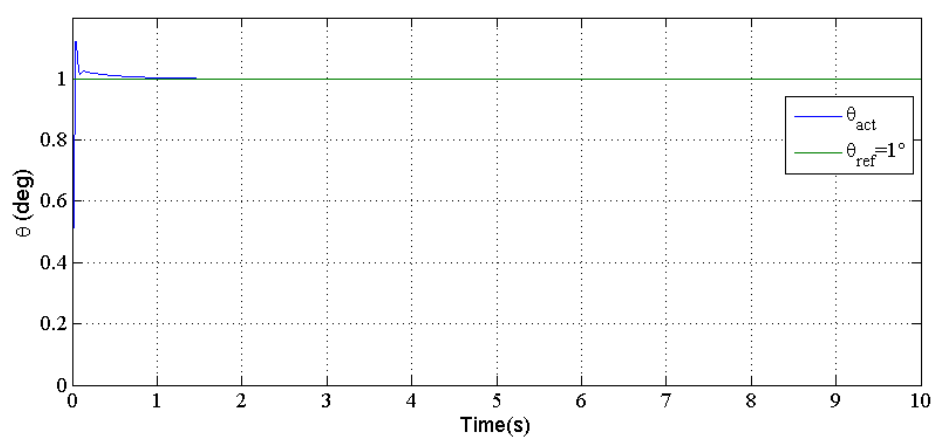

(b)

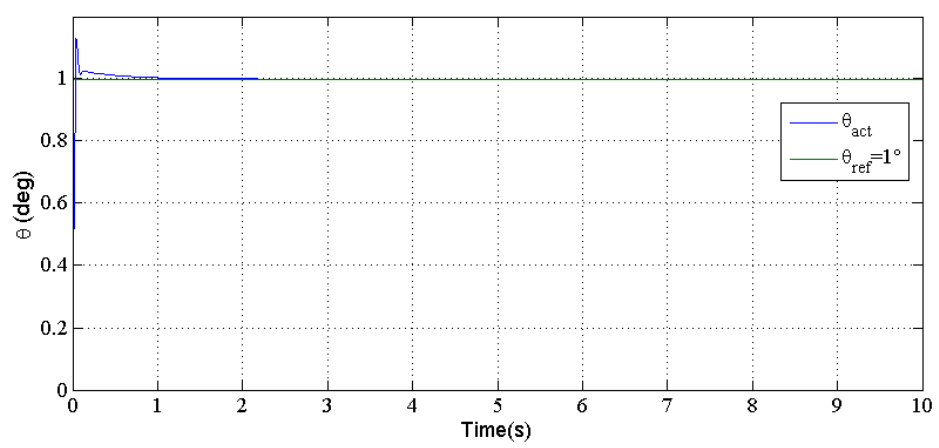

(c)

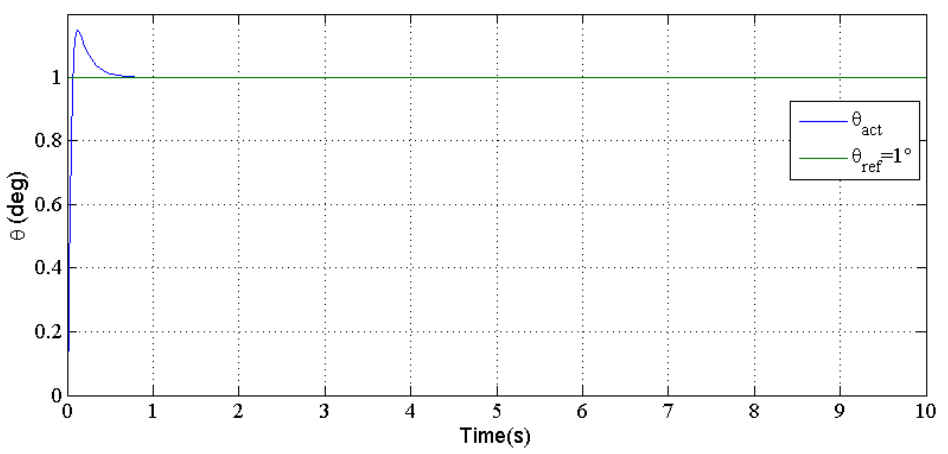

(d) 


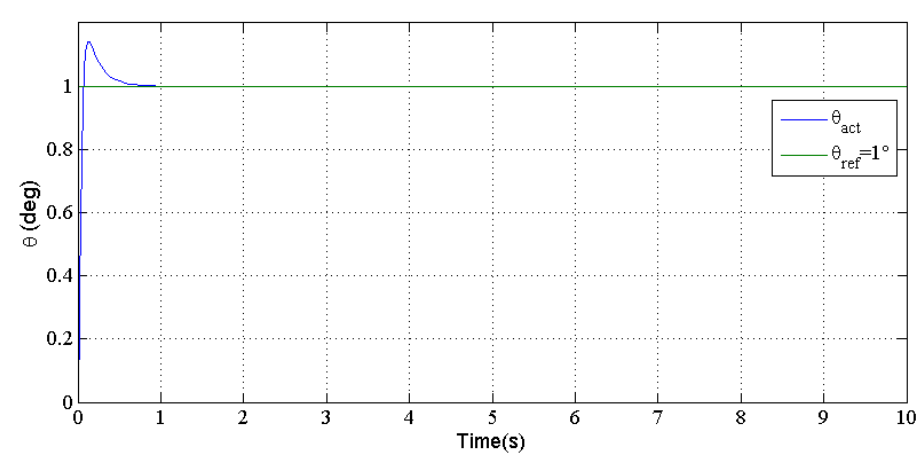

(e)

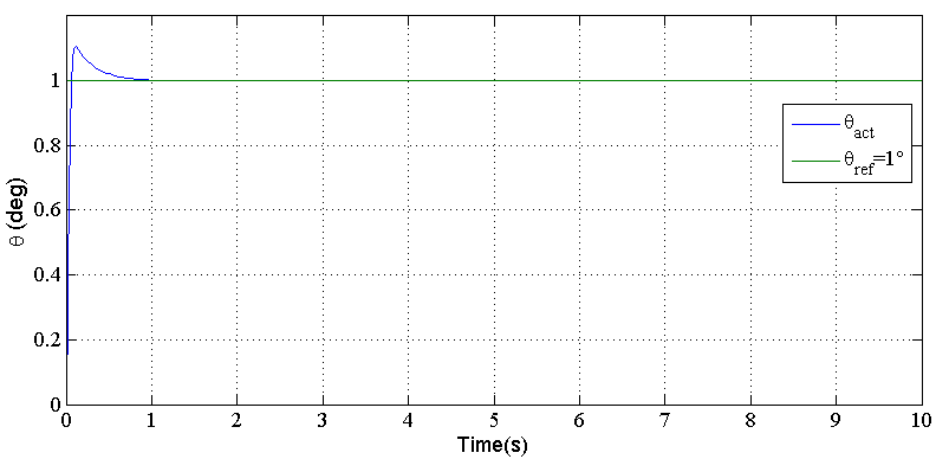

(f)

Figure 14. Simulation result for each random value

\section{Conclusions}

In this article, hexarotor morphing is discussed by longitudinal flight. Determining the moment of inertia and PID coefficients is difficult with analytical methods since the hexarotor arm lengths change in the morphing condition. Therefore, a deep neural network was used to determine the relevant parameters according to arm lengths. For the deep neural network, the moment of inertia values according to the 15 morphing states were obtained from the model drawn in the Solidworks program, and the PID coefficients were obtained from the simulations in the Matlab/Simulink environment. Hexarotor longitudinal flight was controlled by determining 6 random arm lengths according to these values.

$1^{\circ}$ trajectory was followed in longitudinal flight. Create an effect of morphing states on flight according to simulation results. It is possible to see the effect with the design performance criteria such as rise time, settling time and overshoot.

Table 3. Design performance criteria

\begin{tabular}{l|l|l|l|l|l|l}
\hline & $\mathbf{1}$ & $\mathbf{2}$ & $\mathbf{3}$ & $\mathbf{4}$ & $\mathbf{5}$ & $\mathbf{6}$ \\
\hline Rise Time & 0.030 & 0.020 & 0.020 & 0.043 & 0.044 & 0.040 \\
& $9 \mathrm{sec}$ & $6 \mathrm{sec}$ & $1 \mathrm{sec}$ & $2 \mathrm{sec}$ & $6 \mathrm{sec}$ & $7 \mathrm{sec}$ \\
\hline Settling & 0.452 & 0.201 & 0.235 & 0.436 & 0.46 & 0.51 \\
Time & $\mathrm{sec}$ & $\mathrm{sec}$ & $\mathrm{sec}$ & $\mathrm{sec}$ & $\mathrm{sec}$ & $\mathrm{sec}$ \\
\hline Overshoo & 10.2 & 13.7 & 14.5 & 14.9 & 14.4 & 10.8 \\
$\mathbf{t}$ & $\%$ & $\%$ & $\%$ & $\%$ & $\%$ & $\%$ \\
\hline
\end{tabular}

In this study, the effect of morphing and variable UAV parameters on flight was investigated. A more stable and stable flight was achieved by updating the variable parameters during the flight with the Deep Neural Network.

\section{References}

Alaimo, A., Artale, V., Milazzo, C., Ricciardello, A., \& Trefiletti, L. (2013). Mathematical modeling and control of a hexacopter. 2013 International Conference on Unmanned Aircraft Systems (ICUAS), 1043-1050.

ÇOBAN, S., BİLGIÇ, H. H., \& OKTAY, T. (2019). Designing, Dynamic Modeling and Simulation of ISTECOPTER. Journal of Aviation, 3(1), 38-44.

Ko, W., Oo, K., Tun, H. M., Naing, Z. M., \& Moe, W. K. (2017). Design Of Vertical Take-Off And Landing (VTOL) Aircraft System. International Journal of Scientific \& Technology Research, 6(4), 179-183.

Kose, O., \& Oktay, T. (2020a). Effect Of Differential Morphing On Yaw Movement In Quadrotors.

Kose, O., \& Oktay, T. (2020b). Investigation of the Effect of Differential Morphing on Lateral Flight by Using PID Algorithm in Quadrotors. European Journal of Science and Technology, 18, 636-644. doi: 10.31590 /ejosat. 702727

Kose, O., \& Oktay, T. (2020c). The Effect of Differential Morphing on the Hover Flight in Quadcopter. In Bilgisayar Mühendisliği Çalışmaları 1 (p. 59). Iksad.

Kose, O., \& Oktay, T. (2020d). The Effect of Collective and Differential Morphing on Longitudinal Flight in Quadrotors. N. A. B. BAYRAKTAR (Ed.), 10th. International Conference on Mathematics, Engıneering, 
Natural and Medical Sciences (pp. 133-142). Batumi, Georgia: Iksad.

Le, D.-K., \& Nam, T.-K. (2015). A study on the modeling of a hexacopter. Journal of the Korean Society of Marine Engineering, 39(10), 1023-1030. doi:

10.5916/jkosme.2015.39.10.1023

Oktay, Tugrul, \& Coban, S. (2017). Simultaneous longitudinal and lateral flight control systems design for both passive and active morphing TUAVs. Elektronika Ir Elektrotechnika, 23(5), 15-20.

Oktay, Tuğrul, \& Köse, O. (2019). Dynamic Modeling and Simulation of Quadrotor for Different Flight Conditions. European Journal of Science and Technology. doi: 10.31590/ejosat.507222

Pflimlin, J. M., Soueres, P., \& Hamel, \& T. (2007). Position control of a ducted fan VTOL UAV in crosswind. International Journal of Control, 80(5), 666-683. doi: 10.1080/00207170601045034

Sanca, A. S., Alsina, P. J., \& De Jesus F. Cerqueira, J. (2010). Dynamic modeling with nonlinear inputs and backstepping control for a hexarotor micro-aerial vehicle. Proceedings 2010 Latin American Robotics Symposium and Intelligent Robotics Meeting, LARS 2010, 36-42. doi: 10.1109/LARS.2010.14

Wang, L., \& Poksawat, P. (2017). Automatic tuning of hexacopter attitude control systems with experimental validation. 2017 21st International Conference on System Theory, Control and Computing, ICSTCC 2017, 753-758. doi: 10.1109/ICSTCC.2017.8107127

\footnotetext{
Appendix

Definitions, acronyms and abbreviations

$P I D=$ proportional integrator and derivative; $U A V=$ unmanned aerial vehicle;

$V T O L=$ vertical take-off and landing

$G P S=$ global positioning system

$A N N=$ artificial neural network

Symbols

$x=$ position along $\mathrm{x}$ axis;

$y=$ position along $y$ axis;

$z=$ position along $\mathrm{z}$ axis;

$u=$ velocity in the $\mathrm{x}$ axis direction;

$v=$ velocity in the y axis direction;

$w=$ velocity in the $\mathrm{z}$ axis direction;

$p=$ roll rate;

$q=$ pitch rate;

$r=$ yaw rate;

$\phi=$ roll angle;

$\theta=$ pitch angle;

$\psi=$ yaw angle;

$g=$ gravitational acceleration;

$I_{x}=$ moment of inertia about $\mathrm{x}$ axis;

$I_{y}=$ moment of inertia about $y$ axis;

$I_{z}=$ moment of inertia about $\mathrm{z}$ axis;

$w_{g}=$ total propellers' speed;

$w_{1}=$ first propeller speed;

$w_{2}=$ second propeller speed;

$w_{3}=$ third propeller speed;

$w_{4}=$ fourth propeller speed;

$w_{5}=$ fifth propeller speed;

$w_{6}=$ sixth propeller speed;

$f_{t}=U_{1}=$ vertical thrust factor;
}

$\tau_{x}=U_{2}=$ rolling thrust factor;

$\tau_{y}=U_{3}=$ pitching thrust factor;

$\tau_{z}=U_{4}=$ yawing thrust factor;

$m=$ quadrotor mass;

$b=$ thrust factor;

$L=l=$ length of arm;

$d=$ drag factor; 